\title{
EXPLORING EMERGING MENTORING PRACTICES IN NEW ECOSYSTEMS OF LEARNING IN FINLAND
}

\author{
Irja Leppisaari \\ Centria University of Applied Sciences, Talonpojankatu 2, FIN-67100 Kokkola, Finland
}

\begin{abstract}
In this paper we examine the kinds of mentoring models and practices employed in Finnish higher education and working-life to support continuous skill development, focusing especially on the working-life-centric digital mentoring of students. The theme interviews at $11 \mathrm{HE}$ institutions and four enterprises were conducted as part of an eAMK project. The results show that classical and new implementations are employed in mentoring in HE and the workplace. While traditional pair mentoring continues to be the most widely used mentoring model, group and cross mentoring are increasingly utilised. Likewise, an agile combination of different mentoring models is identified as a feature of emerging mentoring practices. Digitalisation is increasingly part of the examined mentoring implementations and in HE especially trials are carried out to develop digital mentoring. Emerging learning ecosystems call for mentoring that is agile, adaptable and digitally accessible. We also examine the viable features and development needs of the presented mentoring models, especially from the perspective of digital devices.
\end{abstract}

\section{KEYWORDS}

Digital Mentoring, Mentoring Models, Mentoring Practices, Higher Education, Working Life, Theme Interview

\section{INTRODUCTION}

Centuries old mentoring has recently risen strongly in Finland as a vehicle for developing performance. Concurrently mentoring - and other education methods - seeks new forms as working-life and ways of working are changing. Challenges to mentoring set by rapid changes to work and the creation of new occupations must be articulated. In this state of change, we strive to update learning and expert thinking (Hakkarainen et al, 2004) on the one hand, and on the other meet the challenges and derive the maximum benefit from the affordances created by digitalisation (see Owen, 2015). Updating mentoring for the digital age is ever more rigorously founded on a constructivist dialogue (Crow \& Grogan, 2017), in which competence is built and professional development promoted by acting together and crossing borders between $\mathrm{HE}$ and working-life. The relationship between digitalisation and mentoring especially arouses a researcher's interest. How is mentoring configured and updated to respond to structural changes in society and digitalisation? There is cause for a specifically proactive setting of this question: How can the affordances of digitalisation be utilised in mentoring? What methods support skill development as required in continuous and lifelong learning? What might the new spaces of mentoring be like?

When digitalisation changes working-life and through this skill needs, it should be seen concretely in mentoring solutions. The need to research new mentoring methods is obvious (Irby et al, 2017). In this article we examine as part of a working-life-centric learning ecosystem theme the mentoring perspectives in digital learning and operational environments raised in the Digital Mentoring of Students action in the Finnish universities of applied sciences' eAMK (means eUniversity of Applied Sciences) project. The initial survey in the project provides perspectives into the kinds of mentoring practices in use to support continuous skill development, especially in the working-life-centric digital mentoring of students. The examination links more broadly to an ecosystem thinking (see Kemmis \& Heikkinen, 2012) which argues that new practices take on features from ambient practices. This sample-based research provides knowledge on one European country's approach to modern mentoring. How technology can be harnessed in a diverse implementation of mentoring and the modernisation of mentoring models for the digital age are extremely topical international issues. Comparable studies do not exist, which indicates the novelty value of this study. 


\section{EMERGING MENTORING}

Innovative, agile, lifelong learning models are called for in the Finnish higher education vision (Proposal for Finland 2030). The rapid rate of change in working-life requires learning to continue throughout an entire career. The emerging mentoring for this digital age offers practices that cross traditional boundaries and can be practised while still studying. Mentoring and coaching are, according to Kampylis, Punie and Devine (2015) identified as methods that guide towards continuous professional development in digital savvy educational organisations. Mentoring can be seen as one significant approach in the new ecosystems of learning, that is development environments in which dynamic cooperation is of benefit to all participants (students, educational organisation and working-life), and sharing of expertise and peer development are key (Boulton-Lewis, Pillay \& Wills, 2006; Hakkarainen et al, 2004).

There appears to be a societal and social need for mentoring at the moment. Mentoring practices have also reached a decisive point. What kind of mentoring is required to respond to structural changes in society and the development needs of new skills? The following observations can be made when mentoring is examined from the ecological principles of ecosystems (see Kemmis \& Heikkinen, 2012). Changes in working-life, digitalisation of education, ubiquitous learning and remote work lead to changes in mentoring as mentoring acquires characteristics from prevailing practices. Establishing a dynamic balance in learning ecosystems may mean that in order to retain its place, practices become more modern to align with challenges arising from the operational environment and changes in work methods. When one model - for example being in a specific physical location at the same time for a mentoring meeting - doesn't work, then another kind of model - a virtual meeting - starts to take life. Changes in mentoring approaches may also be evident in the resonance of mentoring models that support more social, group and peer mentoring rather than one long-term mentoring relationship or even in the building of one's own mentoring network (Leppisaari, 2017; Erickson, 2014).

Developments in learning and expert thinking have led to alternative models to the traditional dyad mentoring model, such as peer mentoring, mentoring groups and networks (Lunsford et al, 2017; Bierema, 2017). Peer mentoring is a typical practice produced by modern developmental mentoring that has increasingly gained ground as the significance of peer learning has strengthened in skill development. Peers mentor each other and increasingly a younger individual mentors someone older. The agile change of roles characteristic of peer mentoring is described in studies (McManus \& Russell, 2007) as fluid expertise, in which an individual is as needed a learner, while at other moments s/he is an expert and is able to seamlessly move between these roles. Group mentoring, in which the wisdom and experience of many people is accessible, can be realised in multiple ways. For example Huizing (2012) analyses the models of group mentoring as follows: peer group mentoring, one-to-many mentoring, many-to-one mentoring and many-to-many mentoring. A group may have one or several mentors who represent, for example, different areas of expertise and/or the group may be based on mutual peer mentoring (see Bierema \& Merriam, 2002; McManus \& Russell, 2007). Belonging, interaction, networking, acting as a role model and psychosocial support are all emphasised in group and peer mentoring. Reverse mentoring, on the other hand, highlights collaboration in which a younger individual with less experience in their career is able to share expertise in specific areas of competence (Murphy, 2012), e.g. digital skills. Cross mentoring refers to mentoring between several organisations (Clutterbuck, 2017). The term is also applied to mentoring between different educational or business fields, or inter-cultural, inter-generational or inter-gender mentoring (Clutterbuck et al, 2017). Network mentoring in this context means that an actor creates a mentoring network for him/herself - either independently or within a specific existing network (e.g. alumni of one's school). Faculty members may through their cooperation with others also assemble for themselves a network consisting of several mentors (Lundsford et al, 2017). The issue is the ability to build diverse relationships that facilitate the development of skills.

The mentoring process can be expanded through the use of digital tools to form virtual mentoring groups and communities. In this case, mentoring is not bilateral interaction, but rather a multilateral learning process with the objective of skill development (knowledge and ability), problem solving, and commitment to working together (cf. Lewis \& Allan, 2005). In summary, mentoring is developing in a non-hierarchical, social and comprehensive direction (Bierema \& Merriam, 2002; Parsloe \& Leedham, 2009) and new lighter deliveries of mentoring are being created, such as flash mentoring (Grindrod, 2016). 


\section{DIGITAL MENTORING IN THE EAMK PROJECT}

In the Finnish universities of applied sciences (UAS) and one scientific university's joint New Ecosystems of Learning - eAMK project (http://www.eamk.fi/en/frontpage/), UAS experts, students and stakeholders combine their strengths and update practice and learning. One action in the construction of working-life-centric learning ecosystems is the development of digital mentoring practices on the student - working-life interface. Digital mentoring in this context refers to mentoring in learning and operational environments that are becoming more digitalised. In the examined project, digital mentoring (equivalent to e-mentoring) is defined as cooperation between two or more people in which all participants desire to develop in a common area of interest (e.g. working-life readiness) and share expertise utilising digital methods and tools in their mutual interaction. The mentor of an undergraduate may be a postgraduate student, alumni or working-life representative. Diverse models of mentoring are utilised, such as group and peer mentoring and cross mentoring in which participants come from different HE institutions, organisations and fields (eAMK-glossary). This definition includes group and peer mentoring and learning in which partnerships, interaction and cross-fertilisation are emphasised. The focus of interest in the project is especially how learning on the student - working-life interface can be deepened with digital methods.

\section{RESEARCH STUDY}

In this article the mentoring landscape in increasingly digital learning and operational environments is examined from the basis of a Finnish research sample. The research task was to ascertain what digital mentoring practices are used in $\mathrm{HE}$ and working-life. The qualitative research sample illustrates as cases the digital mentoring practices of the target groups. An overall picture of the digital mentoring field and its good practices and development needs was gained through the research interviews conducted in autumn 2017 and early 2018. Networking of mentoring practitioners and researchers was also facilitated. The research questions examined in this article are: 1) What kinds of mentoring models/types are used in $\mathrm{HE}$ and working-life? 2) What kinds of mentoring practices are used in HE and working-life? 3) What kinds of good practice and development needs are identified?

The research data $(\mathrm{N}=15)$ comprises the interviews of $11 \mathrm{HE}$ representatives, that is of 10 UASs and one university (data codes further as HEI1-11, Higher Education Institution) and the interviews of four national or global large-scale businesses (data codes further C1-4 Company). Altogether 23 people were interviewed as five of the 15 interviews were conducted as group interviews with 2-3 participants. The interviewees were found by surveying the digital mentoring contact persons of the HEI through the eAMK project's electronic platform (yammer) and through the personal connections of the digital mentoring development researcher. The large-scale business representatives were drawn from contacts on the EMCC (European Mentoring and Coaching Council) Finland's board. Interviewees from HEIs were senior lecturers, principal lecturers or project workers and from the companies they were HR managers. The interviewees were therefore mentoring experts in their organisations and were selected because of the knowledge they were thought to possess on the phenomenon under examination (Alastalo et al, 2017; Flick, 2006). The difficulty of an unequivocal definition of mentoring and its related concepts is acknowledged, and it must be noted that this examination includes approaches that the interviewees have understood as mentoring.

The investigation was conducted as theme interviews, supplemented as needed with documents and research provided by the interviewees. These were semi-structured interviews / focused interviews (see Flick, 2006), discussions which progressed according to an interview framework prepared by the researcher. In this way the researcher does not lock in exact interview questions but rather defines the central themes to be discussed in the interview. The themes took shape through the researcher's earlier e-mentoring studies and research literature on the themes. The content explored mentoring models, implementation, links with working-life, and the use of digital tools in mentoring. Additionally, the interviewees' ideas on what added value and the affordances digitalisation bring to mentoring were ascertained. This question is explored separately in another article. In this article the research perspective is limited to mentoring models and practices. Of the approximately hour long theme interviews, 10 were conducted using the Skype for Business application (video/audio connection) and 5 as contact meetings. The interviewees were well used to video conferences, which made video technology a natural tool in expert interviews (see Alastalo et al, 2017). 
The interviews were saved directly in an electronic form and transliterated word-to-word. The data was analysed and categorised according to interview themes, concurrently engaging in dialogue between the literature and earlier research.

\section{RESULTS}

\subsection{Mentoring Models}

The interviews ascertained the kinds of mentoring models used in HE and working-life. This enabled categorisation of the models as well as ascertaining the role of technology and how it is used in an increasingly digital society.

Finding a common understanding of mentoring as a phenomenon in the interview context was part of the categorisation of mentoring models. In several cases the interviewee expressed uncertainty as to how well his/her case matched the definition of mentoring used in the eAMK project (see chapter 3 above). In the HE context there was reflection on, for example, did mentoring need to be a contract-based sustained long-term interaction or can it be short-term activity on some course? In the business context, mentoring was, at its broadest definition, defined in various terms as learning. One working-life representative described changes in mentoring evident as greater peer and reverse mentoring as follows: "The relationship doesn't need to be like from father to son, but it can be as from colleague to colleague, and it could even be like from me the child to you 'my father'" (C3). While difficulties in defining mentoring and its related concepts (e.g. coaching) were recognised, achieving the desired benefits and outcomes from the activity was more important than what terms are used.

Table 1. What kinds of Mentoring Models are used in HE and Working-Life?

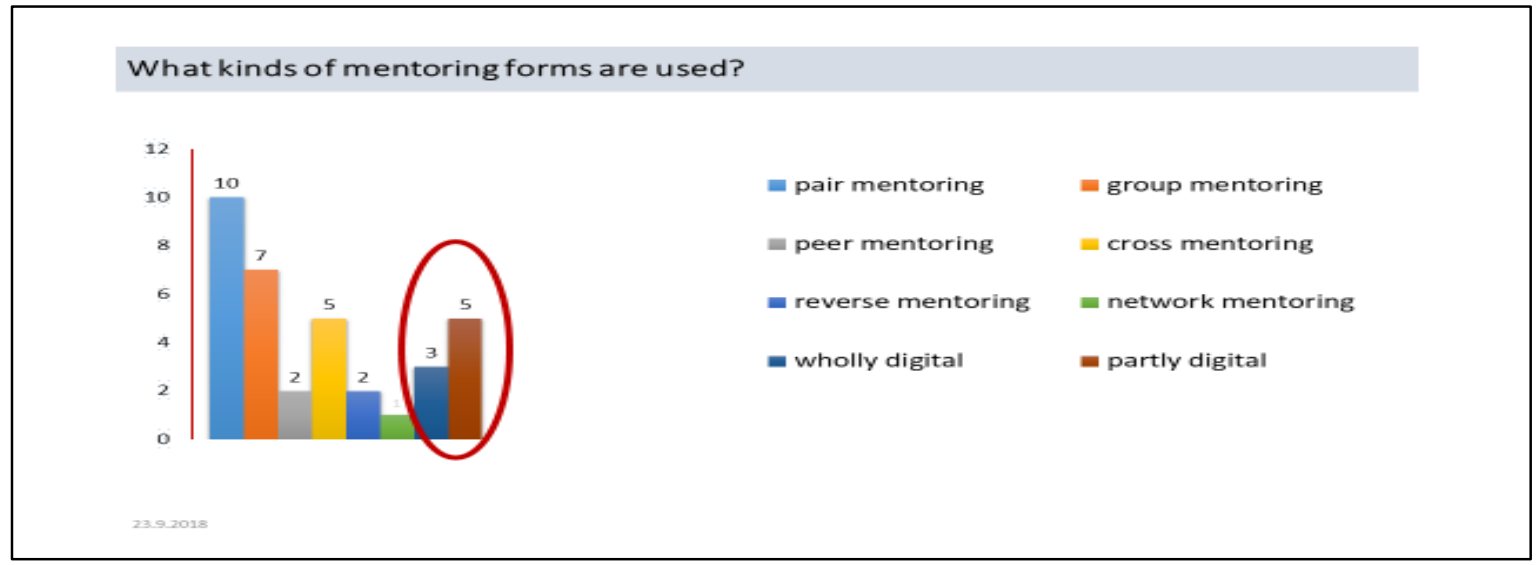

As can be seen from Table 1, pair mentoring was the most used mentoring model in HE and working-life $(\mathrm{N}=10)$. Group mentoring $(\mathrm{N}=7)$ was the second most commonly used model, followed by cross mentoring $(\mathrm{N}=5)$. The mentoring models described in Table 1 are not mutually exclusive; rather the practices examined below in this chapter may, for example, combine pair mentoring with a completely digital interaction, or group mentoring and partial digital interaction. Several models of mentoring may exist in a model, often for example peer mentoring implemented in groups.

Digitalisation often permeates the basic models of mentoring and is an integrated dimension. It is present in an agreed way or - as became evident in some companies - is self-evident in the interaction. An example of an entirely virtually implemented mentoring programme in the research data is the global company. In half of the cases, digitalisation was present in the interaction in some way - as more than just email communication. Perceptions on the significance and added value of digitalisation naturally depend on whether the company is a domestic one operating in one location or a global company operating in over fifty countries.

It is noticeable that companies connected mentoring more often with pair work while coaching programmes were implemented in a group context. However, one company acknowledged that group mentoring entered the 
picture when for example two mentoring dyads perform tasks together within the mentoring programme. One enterprise implemented reverse mentoring in specific programmes in which they wished to show that mentoring can also work the other way round. It was also evident that many companies had as a guiding principle in their mentoring contracts that the issues dealt with benefit both parties, even though mentoring was based on the actor's needs.

In cross mentoring, for example, a teacher can find him/herself a mentor from working life. In one case a cooperation agreement between a UAS, the city and hospital district facilitated mentoring that crossed organisational boundaries. In student mentoring, cross mentoring may mean that the actor/actors and mentor/mentors are from different fields, in which case pair or group mentoring is cross-sector, as in the eGroup mentoring operational model (see 5.2.2). In a business context cross mentoring is limited by competition legislation barriers which restrict the range of topics that can be discussed.

Various models of mentoring were diversely employed by HE and working-life. Classical pair mentoring continues to be the most used mentoring model, but group and cross mentoring models are gaining popularity. The combination of different mentoring types was seen as the future: “...start as e.g. pairs, but then there are devices that also enable peer activity. This doesn't necessarily become a separate mentoring programme, peer mentoring or group mentoring versions, but is rather a kind of extensive entity, and ... is made possible by digitalisation" (HEI6). New light mentoring initiatives are also being created. An emerging mentoring model is flash mentoring (see Grindrod, 2016), referred to by one company representative: "Whatsapp and these types of private group messaging apps are really good, as you get a quick response to a direct question" (C3). In an acute situation, digitalisation allows for the support of a peer or more experienced expert in the network.

\subsection{Practices in Mentoring}

The practices (operational models) employed in the implementation of mentoring at HE and in working-life were surveyed in the interviews. The interviewees were asked to describe their practice of mentoring or their mentoring programme. Sub-questions included: Who are the mentors, who are the actors? What kind of orientation do they receive to mentoring? How is mentoring implemented in practice? How is mentoring activity evaluated? Is internationalisation included in the activity? We endeavoured to identify similar kinds of operational models in the qualitative analysis of the data. This analysis is summarised and illustrated with examples below. Eight different mentoring practices arose from the data. The first five (5.2.1 - 5.3.5) correlate directly with the eAMK project's digital mentoring action of working-life-centric student mentoring, a topic of particular interest, and the final three $(5.2 .6-5.2 .8)$ have an indirect link.

\subsubsection{Digital Mentoring Integrated in a Course}

The first practice to emerge from the interview data was one in which digital mentoring is integrated into a specific course (HEI2, HEI5, HEI10). In one example of this (HEI2), a working-life representative acted as a coach on an e-course (cMOOC) related to the occupational field. The representatives were responsible for, e.g. two small groups. Digital tools employed in this case included: Moodlerooms as a "home base", Padlet and Youtube in learning tasks and Collaborate Ultra in interaction.

In the second case (HEI10) senior students ("the second years") acted as mentors for junior students ("the first years"). Cooperation was implemented in pairs and in groups. Digitalisation was utilised diversely. Students selected digital tools appropriate for their interaction, joint writing tasks and individual reflections (blogs). In certain learning tasks (e.g. production of video interview material), mentors were in contact with alumni around the globe. In this model, students are first actors and then the following year they are mentors. Students themselves plan the process with its functional activities and when acting as mentors they can utilise the experience they gained the previous year. They therefore also act as developers of the operational model.

The third case (HEI5) in which digital mentoring was integrated into a course is the cross-sector course which made use of coaching. Postgraduate social sciences, international cooperation and technical engineering students coached each other and collaboratively developed intelligent solutions for Finland's current social services and healthcare reforms. Social sciences postgraduate students contributed innovations from working-life and these were peer developed with technology students and international partners on the principle that the innovations that best meet future megatrends are created on interfaces. 


\subsubsection{Digital Mentoring as a Course}

The second model that arose from the examination of digital mentoring practices is digital mentoring as an individual course (HEI1, HEI5, HEI4). An example of this (HEI1, HEI5) is the collaborative delivery of eMentoring training by three UASs. An elective course for degree programmes was created in an ESF funded project and this educational collaboration continues even though the project has ended. In this model students execute a new kind of mentoring as part of their studies. Postgraduate students (eMentors) and/or alumni mentor undergraduates (eActors). For eMentors the course scope is 5 credits and for eActors 3 credits. The course is 8 months in duration and consists of real-time educational contexts, web-mediated work and mentoring practice. Mentoring is implemented as cross-sector eGroup mentoring and design-based research methods are applied to continuously refine the model further. A diverse trialling of digital tools is a key part of the model: mentor-actor groups choose their own tools for interaction, for collaborative work on documents and instant messaging. Moodle and the Skype for Business video conferencing system are employed in the training. By autumn 2018, 48 eMentors and 43 eActors had completed the course. Another course implementation in the data (HEI4) is the Mentoring and Student Counselling course (5 credits) offered to students in the final stages of a healthcare programme.

\subsubsection{Mentoring Integrated into Education as a Pedagogic Solution}

The third working-life-centric student mentoring practice that emerged from the interview data (HEI4, HEI7) is the integration of mentoring into an entire education programme - more extensively than just one single course - as a pedagogic solution. In the example case (HEI4), students are assigned their own mentor in a satellite education. The students are all in working-life, and working-life needs inform the content of education. This needs-informed model aims to strengthen adult learners' professional performance. The mentor and student draw up a mentoring agreement according to which mentoring discussions are engaged in at least twice during an academic year. The student reflects on his/her learning through writing, video or podcasts in his/her own personal learning environment (blog), where the mentor also gives feedback on the student's learning. This ensures the close involvement of a working-life representative in the student's PLE (Personal Learning Environment). In this practice mentors receive training for their task in a mentor coaching programme. Essential to the mentor's performance are an ability to evaluate knowledge and skills, and an ability to give feedback and guide the student's reflection.

A second case (HEI7) in which mentoring is integrated as a pedagogic solution is the Enterprise Accelerator model. This model has been developed and delivered at a UAS for 20 years and covers the areas of developing a business idea, working as an entrepreneur, and developing a business. A student in the Enterprise Accelerator is assigned his/her own accelerator mentor, who may be a teacher with a business. The operational model is linked to all degree programmes.

\subsubsection{Project-based Mentoring Programmes for HE Students}

The fourth model to emerge from the interview data was project-based mentoring programmes for HE students. An example of this practice (HEI6) is firstly one UAS's partnership with a Chamber of Commerce in delivering a mentoring programme. Thirty mentor-actor pairs participated in the first implementation of this programme with 14 pairs in the second. Mentors were managers or leadership level staff from the Chamber of Commerce's member companies. Actors were provided an opportunity to network with the mentors and leverage the latter's supervisory and leadership experience. Mentors and actors apply for the programme and a selection group from the Chamber of Commerce's work and education committee match pairs. The mentors and actors are often from different fields and this cross-sector dimension enables reciprocal challenging and sparring. The one year programme begins with coaching of mentors and includes one interim meeting. At the time of the interviews, the actors' participation had not been assigned any credit point value, but in future the programme will be linked to the final stages of Professional Growth studies.

The second case (HEI11) in project-based HE student mentoring programmes was the use of alumni as mentors in career guidance. Mentoring is executed in pairs in this model. Mentors were sought "by hand" to meet the actors' specific needs in mapping a career path. Student interviews played an important role in the recruitment of actors. One hundred mentor pairs participated in the three year programme which includes orientation and closing events; otherwise the pairs engage in self-directed work, meeting 4-8 times during the year. Mentoring is an elective course (max. 2 credits) in the final stages of studies. The learning process is verified through the students' learning journals. The school has deliberately decided on face-to-face meetings, 
unless exceptional situations, such as a mentor's move abroad during the process, prevent this. Digital elements can, however, be included in the process, as each mentor pair has the freedom to choose how they work and which tools of communication they use.

\subsubsection{Alumni Mentoring in a New Way}

A model, still in the development stages at a HEI, representing new mentoring practices is alumni mentoring to foster career guidance through career narratives (HEI9). Mentoring is deliberately "turned upside down" and instead of previous mentoring programmes with a credit scope a new lighter operational model in which alumni share their career narratives on an electronic platform is developed. The HE representative justified the development of the model by explaining that students resonate with different career alternatives. The student listens to the narratives and chooses who s/he wants as a mentor and may, if s/he so wishes, contact several individuals. This provides the student an opportunity to form a mentor network to meet his/her needs, rather than identifying one "perfect" mentor (see Erickson, 2014). The school in question has an extensive and robust alumni register system which creates the right infrastructure for the trialling of this new kind of practice. Networking and a sharing of career narratives as a form of coaching is considered a more agile practice than the pair formation previously conducted by the school. A digital platform appropriate for career narrative "shopping" has yet to be found. The aim of the development work is to support cross-sector collision of students which allows them to think and see "out of the box". This is a non-credit model based on voluntary participation of both parties, which is considered to strengthen commitment to the activity. If a student wants credits for the programme, a means of verifying learning is customised with the student. Opportunities for a mentor to meet other mentors are created in the programme, for example in events and a common digital platform.

\subsubsection{Digital Mentors Developing Staff Digital Skills}

Digital mentoring of staff to develop digital skills indirectly impacts student mentoring and is a timely practice in Finnish higher education (HEI1, HEI4, HEI5, HEI8, HEI10). Digital mentors are staff members who support their colleagues in the uptake of digital devices in teaching. In this context digitalisation is the target of mentoring that is it is the content to be learned, while in our research digitalisation is primarily a tool in working-life-centric mentoring of students. Digital mentors mentor other teachers in the use of digital devices; this activity is also seen as peer mentoring. For example, an entire department may be supported in this way. Mentoring related to the development of staff performance may also include orientation of a new teacher or pair mentoring between colleagues to develop teaching practice or a specific course. The nature of teaching is increasingly perceived as mentoring or coaching (see Kampylis et al, 2015). Teachers act as coaches in, for example, learning projects in which first-year students are "thrown" into working-life. The use of mentors in staff development also provides teachers with models for their own work.

\subsubsection{Develop and Produce Mentoring Services for Working-Life}

Over half the interviewed HEIs and two of the companies develop and produce mentoring services for working-life. This occurs in RDI education development projects in which HE teachers or project workers develop working-life. The integration of theory and practice concurrently benefits HE instruction. One UAS implemented a peer mentoring project (which also included cross mentoring and digital mentoring) to support encounter and workplace wellbeing of professionals in a small-scale workplace. In this case, the role of the HE project worker was to provide, using a partner approach, technical support for the mentoring process and the partner in turn provided content facilitator support. In one case, peer mentoring between micro-businesses and large-scale businesses was implemented in workshops in which HE teachers facilitated the process and students contributed the latest knowledge in their area of study.

Mentoring training with various content and targets is sold to workplaces: e.g. coaching for a hospital district, or business successors, or supervisor coaching for city leaders. One HEI offers as paid continuing education mentor training for employed healthcare professionals who provide guidance to UAS healthcare students. The healthcare professionals already have training in supervising students on their practicum. Companies may also have a mentoring programme targeted at external groups, e.g. young female students, as part of their corporate social responsibility and voluntary schemes. 


\subsubsection{Virtual Mentoring Programme for Company Staff}

The eighth operational model $(\mathrm{C} 1, \mathrm{C} 2, \mathrm{C} 3)$ to emerge from the interviews is a virtual mentoring programme for staff in a company. All the interviewed companies engage in some model of mentoring: as part of leadership development or global mentoring programmes, integrated into a talent programme, or pair mentoring offered in career development discussions as one alternative to achieve set goals. The aim is also to develop mentoring programmes open to all employees.

When a global enterprise operates in about 30 countries, mentoring naturally has to be organised as a virtual mentoring programme. In-company mentoring in companies operating internationally can be organised between different lines of business/units. In one case company, at any given time 130-150 pairs participate in a mentoring programme, in which pair formation deliberately supports diverse competence as a working-life meta-skill through the formation of "as disparate pairs as possible" (C2). Pair formation in a mentoring programme can also support inter-cultural skills. Mentoring programmes in companies are usually about half a year comprising 6-9 meetings or they can be shorter, for example 3-6 months. Meetings are arranged through applications and software (e.g. Skype for Business or WebEx) in everyday use and therefore already familiar to participants. One company with mentoring as part of the normal work process (cf. discrete mentoring programmes) has a material bank in its Intra containing explanations of the process, disseminated materials, descriptions of the roles and responsibilities of mentors and actors and confidentiality issues. The typical structure of a mentoring programme includes an initial orientation/info session, possible interim meeting(s) and a closing/feedback meeting. The mentoring programmes of the companies interviewed are based on pair mentoring, but during the interview the interviewees identified peer, reverse and group mentoring dimensions. One company considered that mentoring also built the organisation's internal support network in problem solving, as "there is always someone in a big company who knows what should be done" (C3).

Some of the mentoring models and approaches described in this chapter are based on an expert-novice model; in others elements of community and peer learning as well as shared expertise more strongly underpin practice. The practices fit along a continuum. The following models can be identified as the continuum's extremes in a HE context: a) an experienced mentor guides a soon-to-graduate student, b) the group comprises people at different stages of expertise from different fields and the mentor's and actor's roles change seamlessly in the process. Also typical is that the operational model has features from several mentoring models, even though one specific solution might be the so-called main solution. Cooperation and interaction models which include student participation and diversely benefit the various parties (university, UAS, micro-businesses, large-scale enterprises) emerge as especially interesting in an examination of mentoring as part of a working-life-centric learning ecosystem. The cases also indicate that digital mentoring as an operational model expands learning networks in an international direction.

\subsection{Emerging Mentoring - Viable Practices and Challenges for Development}

\subsubsection{What Works in our Practice}

The strengths and development challenges of the employed mentoring practices were diversely and reflectively considered in the interviews. Identified strengths included learning partnerships between $\mathrm{HE}$ and working-life, support in the development of professional expertise, and a joint development of working-life practices. A "robust and direct connection" (HEI11) to working-life, to quote one interviewee, was evident in the HE models. In practice this connection was formed by, for example, postgraduate students already in the workplace or alumni mentoring undergraduates. In one HEI's three-stage mentoring model (see chapter 5.2.1) alumni are the student mentors' learning resource. A connection with working-life is also created when a working-life representative acts as a mentor in workplace commissioned learning projects. In the above case of alumni mentoring (see 5.2.5), UAS students need to engage in self-directed networking with working-life.

Mentoring was considered a viable means to develop performance. One company representative described mentoring as a skill development model that is light, scalable for different contexts and easy to implement as compared to other educational type solutions. Concurrently self-direction and taking responsibility is realised so that there is no "spoon feeding of ready packaged issues into people's mouths" (C2). Another company representative summarised the significance of mentoring as follows: "I strongly believe in this mentoring, it is like one of the stronger tools to develop individuals and organisations, in leadership and also in these hard professional skills" (C3). The interviewees all perceived that the mentoring models they described supported 
learning of meta-skills (e.g. problem solving skills, self-direction and self-regulation, interaction skills, teamwork skills, cf. Binkley et al, 2012). Networking as an advantage and strength of mentoring was specifically raised by HEIs. In this data, mentoring programmes in companies were in-house.

Students often participate in the development of mentoring models in HE. For example, they plan the mentoring process group-specifically or are involved in the development of new kinds of digital mentoring implementations. In a few cases the opportunity to build a mentor's career path was identified as a good practice. Also, students who are first actors have experience-based knowledge on how to develop the model when they work as mentors. Constructing the process allows students to define the level of challenge and strive towards exceeding their own learning while simultaneously linking theoretical knowledge as a mentor to reflection on learning. Open spaces and complex processes as authentic tasks (see Herrington, Reeves \& Oliver, 2010), for which participants gather research knowledge, teach, according to the interviewed HE teachers, working life skills more effectively than ready-made models.

Both $\mathrm{HE}$ and companies felt that it was a considerable advantage if the operational model provided a genuine opportunity to learn encountering on the internet, engage in dialogue and build trust. Company representatives raised investing in encounters that build trust in a digital operational environment at the start of the process as a good practice. One global company representative felt that contact meetings, however, increased trust much more than mere virtual contact:" (Digitalisation) is a good helper in a global environment, but does not rule out the need for some kind of face-to-face dimension." (C1) The online sessions of companies established connections between people in various visual ways, for example, by using images and lifelines. Good practices identified in virtual multicultural mentoring deliveries included the use of participatory digital tools other than those based on speech, e.g. writing on a whiteboard, mini survey or tick the box. The need to strengthen visual communication was recognized, as video and image mediated communication is universal digital communication which can transcend language barriers.

\subsubsection{Areas of Development in our Practices}

The practices described in the interviews also have development needs and ideas. Of the mentoring models, reverse mentoring is the one that is most felt to need developing: "The average age in our company is quite high, so it might do real good" (C2). HE representatives were also interested in cross mentoring as a focus of development. Mentor dyads could come from different schools: "It would in fact be great to have mentor dyads formed between different HEIs. In such a way that backgrounds are totally divergent... so that one really refutes the thinking that they haven't come from too similar a mould" (HEI9). Digitalisation was seen to afford good opportunities for cross mentoring.

The use of postgraduate students as mentors interested several HE representatives. The development of alumni mentoring was also raised as a development challenge. Alumni should be utilised more strongly in the final stages of study as student support, e.g. partner mentors within group mentoring. Development of alumni mentoring should also be informed by work experience needs: "...when students leave us for their practicum, alumni could take them under their wings and be a link between $\mathrm{HE}$ and graduation... you know about the school culture a little bit more than someone who has studied at another school" (HEI9).

$\mathrm{HE}$ and companies both considered the digital development of mentoring as a development need: a digital platform is needed to administrate mentoring activity and digital tools for the mentoring process. A viable, mobile-usable and diverse digital platform needs to be found for mentoring programmes. In a virtual environment, the accumulating documents are a basis for monitoring the development of the mentoring process with the affordances of learning analytics. One interviewee observed that mentoring programmes based on pair mentoring also needed "...a virtual platform for sharing experiences during the mentoring programme, tools that enable peer and group activity" (HEI6). Companies identified video conferencing as a basic tool of digital mentoring, as discussion is the primary activity in mentoring. Various solutions were found for the sharing of material and other functions. Tools used in other forms of communication were primarily employed in mentoring. According to one interviewee, mentoring programmes should support readiness to uptake new digital devices: “... they would be such that could also be utilised elsewhere....using a few of these and of course that they would inspire to trial and find something new and to try... as technology develops so rapidly that if you use a lot of time in learning something, in a year's time it is wasted time" (HEI1). On the other hand, interviewees who were seeking a specific mentoring tool/app indicated that there wasn't just a need for a bunch of tools, but rather the tools in question needed an in-built methodology based on mentoring research and good practices identified in this. Existing social media or learning environment-based solutions did not meet these needs, as they have not been built for mentoring spaces, but are often a collection of tools (material bank, 
discussion forum, chat, blogs, etc.) that aim to share information and are not underpinned by a deeper understanding of mentoring as a phenomenon and interaction contexts.

One development need that emerged both in HE interviews but was especially raised in company interviews was the need for a real-time mentor bank/pool and its maintenance. A mentor bank would be an advantage for companies, as one representative describes: "Of course it would be really great if there was some kind of mentors-actors bank. Where you could just go and get and make contact and say, hey, you are in that bank and your profile seems to fit, so could we begin a partnership?" (C2) The need to create and match profiles could be met by the affordances of artificial intelligence (AI): "I dream about there being a robot who is able to make that pairing, that it just needs key words fed into" (C2). Digital methods could also be used to update profiles in real-time - a real-time list of alumni mentors available at the start of a mentoring programme.

Further areas that emerged as development needs were orientation to mentoring in digital operational environments and appropriate organisation of process support for busy professionals. The use of digital devices in shorter and lighter models was seen to require thorough orientation for interaction to support learning. It is noteworthy that digital mentoring does not only require mastery of digital tools, but above all the mastery of interaction in a digital environment, or a "dialogue leap", as one interviewee (HEI5) expressed it. How each device supports dialogue and what kinds of frameworks it creates for interaction needs to be explored further. How should technology develop for it to support a feeling of presence? The significance of video image in creating presence was emphasised in undivided attention in interaction. Interaction in digital mentoring also needs to be a focus in inter-cultural communication, as a mentoring process may be a learning experience that changes attitudes and even the participant's life if the participants can learn together how to overcome cultural clashes. A need for an open mentoring orientation material bank that teaches how to act as an actor and/or mentor online emerged in the interviews. Working in a digital world also raises ethical questions related to mentoring, guidelines for which the interviewees wanted general rubrics (cf. ethical guidelines of EMCC).

In several cases, monitoring and evaluation of the process as well as development research were raised as development challenges in mentoring. These need to be more deliberately integrated to the mentoring process. Many of the cases described in the interviews lacked an in-built systematic process evaluation of the mentoring programme. Feedback was collected at the end of the programme and in some cases also in interim meetings. One practitioner described that during the process, "above all else, how the relationship worked was monitored" (HEI6). In companies, post-monitoring of a mentoring programmes' impact might occur, for example, one year after participation. Emerging learning analytics may bring new tools for structuring and monitoring the mentoring process as well as examining the qualitative impact of mentoring. The in-process quality assurance challenges which emerged in the interviews will partially be met by the digital mentoring quality cards to be produced in the eAMK project.

\section{REFLECTION AND CONCLUSIONS}

Digital mentoring models and practices used in $\mathrm{HE}$ and companies were surveyed through theme interviews in an eAMK project. The examination particularly focused on working-life-centric student mentoring. We also endeavoured to outline how digital mentoring, and mentoring more broadly, is situated in the new ecosystem of learning (cf. Kemmis \& Heikkinen, 2012) and how it presents as a pedagogic solution on the interface between $\mathrm{HE}$ and working-life. On the basis of the interview research results, it can first be stated that mentoring as a concept is understood broadly and defined context-specifically. Especially in the HE mentoring cases, features of mentoring and coaching were often combined (see Parsloe \& Leedhamn, 2009). Both classical and new models of implementation are used in mentoring. Digitalisation is increasingly included in the examined mentoring deliveries and HEIs in particular engage in trials which aim to develop digital mentoring as separate social implementations. The increasing need to use digital devices in mentoring generated by a new generation of students and workers is acknowledged, resulting in more and more new mentoring models which combine different models and practices being trialled.

Work, learning and development will in the future form an even stronger indivisible entity. Ubiquitous learning with its decentralised learning spaces will strengthen (Heikkinen, 2017). Mentoring seems to situate into this new emerging ecosystem of learning well. Digitalisation enables the crossing of physical and organisational barriers and the construction of new kinds of social and cross-sector learning spaces on the interface between education and work. When best chosen, the needs of HE to develop new kinds of 
working-life-centric pedagogic operational models and methods to develop professional development for increasingly digital operational environments meet the needs of working-life to create new skill development models. Companies identified a clear need to modernise skill development practices in such a way that it is possible to move from local implementations to wider operational environments. The slow rate of change in an organisation's operational culture, also in mentoring, was acknowledged by company representatives. This study did, however, indicate that alongside classical mentoring concepts, HE is engaged in innovative trials of new kinds of agile and also lighter mentoring models, listening to both students and working-life representatives. HE recognises that in the digital world there is a need for interactive skills in completely new arenas, and mentoring processes facilitate the learning of these skills. Do global large-scale companies have something to contribute to HE in this area, for example as experiences and accrued knowledge in the building of virtual relationships based on presence and trust? These kinds of needs and perspectives could lead to fruitful collaborative development among HE and working-life organisations. Learning spaces in which learning from each other is facilitated will be created in this current eAMK project through a joint development webinar.

The research results indicate that emerging ecosystems require mentoring in which digitalisation is embedded into the mentoring process. Participation in the mentoring process should be easy wherever one is through mobile mentoring, where mentoring travels "with you in your pocket". In the future, digitalisation will lose its significance as a prefix in mentoring and will inherently meld into the different practices of mentoring. The research data indicate that mentoring with its long tradition as a form of learning is agile and able to adapt according to current challenges and affordances of digitalisation. The modernisation process may result in new models and methods of mentoring applicable to today. The new practices in peer and group mentoring which take advantage of digital mentoring, and are therefore rapidly scalable, offer equitable ways to coach and support people. Likewise the flexible combination of different mentoring models appears to be a strengthening feature in emerging mentoring practices. Cross-sector participation can be meaningfully employed in mentoring. It efficiently fosters learning of working-life meta-skills. The newest models of mentoring support learning in networks and peer networks. A student creates for him/herself, for example, a mentoring network for flash mentoring rather than seeking one mentor who should be able to meet his/her different learning needs.

It is obvious that agile and customised mentoring type approaches occupy a central position in career-long professional development (cf. Proposal for Finland 2030). Therefore familiarisation with mentoring models and practices while still at school presents as a significant part of working-life skill accruement in HE. Student-centric mentoring implementations also support the career path of mentoring. At its best, a HE student can during his/her studies first be an actor and in later stages of studies a mentor. The result of this process is equipping the student with models that can be applied in career-long professional development.

The landscape opened up by this study challenges the various mentoring practitioner groups, developers and technology experts to a closer collaborative development of modern mentoring. Further research is needed to deepen knowledge on the use of technology in mentoring as well as for a comparison of digital mentoring practices of different countries and learning from each other.

\section{REFERENCES}

Alastalo, M. et al, 2017. Asiantuntijahaastattelu (Expert Interview). In M. Hyvärinen et al (Eds.) Tutkimushaastattelun käsikirja Vastapaino, Tampere, pp. 214-232.

Bierema, L. L., 2017. eMentoring: Computer Mediated Career Development for the Future. In L. G. Lunsford et al (Eds.). The SAGE Handbook of Mentoring. London: SAGE Publications Ltd, pp. 482-498.

Bierema, L. L. \& Merriam, S. B., 2002. E-mentoring: Using Computer Mediated Communication to Enhance the Mentoring Process. Innovative Higher Education 26(3).

Binkley, M. et al, 2012. Defining Twenty First Century Skills. In P. Griffin et al, (Eds.) Assessment and Teaching of 21st Century Skills. Springer Science+Business Media. B.V.

Boulton-Lewis, G. et al, 2006. Changing Workplace Environments, Conceptions and Patterns of Learning: Implications for University Teaching. In P. Tynjälä et al (Eds.), Higher Education and Working-Life. Collaborations, Confrontations and Challenges. Oxford: Elsevier, 145-161.

Clutterbuck, D., 2017. Cross mentoring - mentoring between companies. Available: https://www.davidclutterbuckpartnership.com/cross-mentoring-mentoring-between-companies/.Accessed 26.11.2018.

Clutterbuck, D. A. et al, 2017. The SAGE Handbook of Mentoring. London: SAGE Publications Ltd. 
Crow, C. M. \& Grogan, M., 2017. Mentoring in Educational Leadership for Organizational Transformation. In D. A. Clutterbuck et al (Eds.). The SAGE Handbook of Mentoring. (pp. 436-450). London: SAGE Publications Ltd.

Erickson, T., 2014. Mentoring for Gen Xers. In HBR Guide to Getting the Mentoring You Need. Boston: Harvard Business Review Press, pp. 143-149.

Flick, U., 2006. An Introduction to qualitative research. Third Edition. London: SAGE Publications Ltd.

Grindrod, S., 2016. Mentoring is Now Changing the Workplace through Technology. Available in Wiley Online Library. Accessed 12.7.2018.

Hakkarainen, K. et al, 2004. Communities of Networked Expertise. Professional and Educational Perspectives. Earli. Oxford: Elsevier.

Heikkinen, H., 2017. Oppimisen uusi ekosysteemi. (A new ecosystem of learning). eAMK-seminar 14.9.2017. Helsinki. Available: https://www.slideshare.net/eamkhanke/oppimisen-uusi-ekosysteemi. Accessed 2.12.2018.

Herrington, J. et al, 2010. A guide to authentic learning. New York. Routledge.

Huizing, R. L., 2012. Mentoring Together: A Literature Review of Group Mentoring. Mentoring and Tutoring: Partnership in Learning 10 (1), 27-55.

Irby, B.J. et al, 2017. New Horizon for Mentoring Research: Exploring the Present and Past to Frame the Future. In D. A. Clutterbuck et al (Eds.). The SAGE Handbook of Mentoring. (pp. 119-137). London: SAGE Publications Ltd.

Kampylis, P. et al, 2015. Promoting Effective Digital-Age Learning - A European Framework for Digitally Competent Educational Organisations. European Union. Available: http://publications.jrc.ec.europa.eu/repo. Accessed 2.9.2018.

Kemmis, S. \& Heikkinen, H., 2012. Future perspectives: Peer-Group Mentoring and international practices for teacher development. In H. Heikkinen et al (Eds.) Peer-Group Mentoring for Teacher Development. Milton Park: Routledge, pp. 144-170.

Leppisaari, I., 2017. Exploring principles of successful eGroup mentoring on the interface of higher education and working life. In J. Dron \& S. Mishra (Eds.), Proceedings of E-Learn: World Conference on E-Learning in Corporate, Government, Healthcare, and Higher Education Vancouver, British Columbia, Canada: AACE, pp. 391-404.

Lewis, D. \& Allan, A., 2005. Virtual Learning Communities. A Guide for Practitioners. Open University Press. Berkshire: McGraw-Hill Education.

Lunsford, L. G. et al, 2017. Mentoring in Higher Education. In D. A. Clutterbuck et al (Eds.). The SAGE Handbook of Mentoring London: SAGE Publications Ltd, pp. 316-334.

McManus, S. E. \& Russell, J. E. A., 2007. Peer Mentoring Relationships. In B. R. Ragins \& K. E. Kram (Eds.) The Handbook of Mentoring at Work Thousand Oaks: Sage, pp 273-297.

Murphy, W. M., 2012. Reverse mentoring at work: fostering cross-generational learning and developing millennial leaders. Human Resource Management, 51 (4), 549-574.

Owen, H. D., 2015. Making the most of mobility: virtual mentoring and education practitioner professional development. Research in Learning Technology, 23(1), 25-56.

Parsloe, E., \& Leedham, M., 2009. Coaching and Mentoring, Practical Conversations to Improve Learning. London: KoganPage.

Proposal for Finland (2030). Vision for higher education and research in 2030. Available: http://minedu.fi/documents/1410845/4177242/Proposal+for+Finland.pdf/08a7cc61-3e66-4c60-af75d44d1877787d/Proposal+for+Finland.pdf.pdf. Accessed 4.12.2018. 